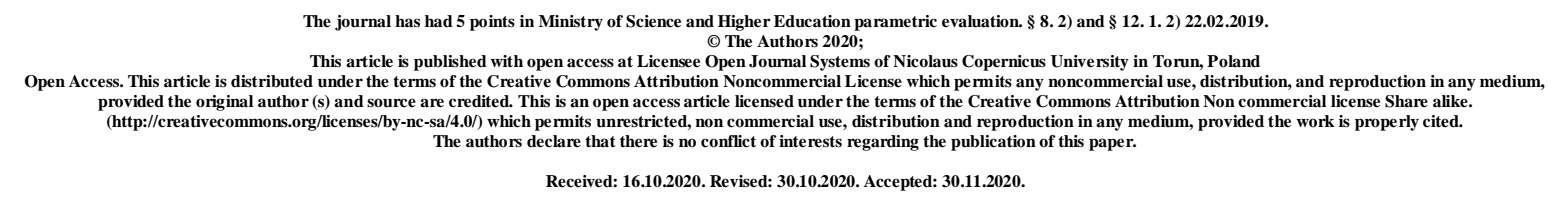

UDC 378.146: 375

\title{
PREPARATION OF FUTURE TEACHERS OF ART DISCIPLINES FOR INNOVATIVE ACTIVITY IN CHINA
}

\author{
Sun Jingqiu, Tan Xiao, Ji Yiping
}

\section{H. S. Skovoroda Kharkiv National Pedagogical University, Ukraine}

Sun Jingqiu, 2564610@qq.com

Tan Xiao, 605651334@qq.com

Ji Yiping, 4485053@qq.com

\section{Abstract}

The article is devoted to substantiation of theoretical aspects of the problem of preparation of future teachers of art disciplines for innovative activity in China. The preparation of future teachers of art disciplines for innovation is considered by the authors as a system, as it can be described as an ordered set of interconnected components, which is a holistic formation. Among such components of the system are the purpose, content, methods, forms, means and so on. Readiness for innovative professional activity is considered by the authors as an integrative quality of personality, which is formed due to the emergence of a psychological system of activity, and its structure is identical to the structure of the corresponding functional psychological system. The components of such a system are the motives and goals of the activity, its information base and program, the decision-making unit and the subsystem of personality qualities, which is professionally important. It is proved that readiness and ability for innovative activity is provided by efficiency of introduction of the newest achievements of science, creative mastering of the advanced pedagogical experience 
of education, search of the most rational means of optimization of educational process and extracurricular activity of future teachers of art disciplines (group work, problem scientific groups, societies, etc).

Key words: professional training; future teachers; art disciplines; innovative activity; institution of higher education; People 's Republic of China.

\section{Relevance of the research}

In modern society, the need of the economy for qualified professionals with professional mobility, able to work in volatile economic conditions.

Currently, scientists are faced with the task of improving the quality of training of modern professionals, which is determined by the requirements of the labor market, employers, the digital economy as a whole. The result is significant changes in education at all levels. Innovative activity and personal component of the effectiveness of pedagogical creativity of art teachers are new integrated concepts, the advantage of which is that they combine professional activity with personal development, spirituality and active humanistic position. These concepts synthesize many different and multilevel aspects of student preparation for professional self-realization, the ability to increase the achievements of the spiritual culture of mankind. The core of these innovations is the readiness of the future teacher of art disciplines to innovative activities as a strong-willed instruction of the individual to achieve high results in professional activities, creative and professional acme.

The introduction of innovations into pedagogical contexts is associated with socioglobalization, market-economic and integration challenges facing education at the turn of the century. Prospects for the development of Chinese higher education, built on the principles of innovation, mobility, democracy are outlined in the legal framework.

\section{Analysis of previous research}

Theoretical and methodological understanding of the researched problem is carried out by Ukrainian and foreign scientists in the following aspects: tendencies and features of development of higher pedagogical education (S. Vitvytska, O. Gluzman, N. Nychkalo, V. Slastyonin, etc.), innovative processes in the conditions of continuous education (V. Andrushchenko, V. Lutay, S. Sysoeva), professional training (S. Arkhangelsky, N. Kuzmina), theoretical and applied issues of preparation for innovative pedagogical activity (I. Gavrish, L. Danylenko, I. Dychkivska, M. Clarin ). 
Analytical understanding of the scientific achievements of the mentioned authors convinces that innovation is one of the main trends in human development, this problem is especially relevant in China.

The purpose of the article is to reveal the theoretical aspects of the formation of the readiness of the future teacher of art disciplines for innovative activity in China on the basis of the analysis of the psychological and pedagogical literature.

\section{Presenting main material}

In the People's Republic of China, issues of educational development are included in the system of main priorities of the social policy of the Chinese leadership. This is about the development and optimization of the educational system. Therefore, the modernization of art education is manifested in the transformation of the organizational foundations of teacher training in art disciplines, in the pursuit of unification of art education and improving the quality of teacher training, achieving in this regard world educational standards.

Currently in the People's Republic of China, aesthetic education and upbringing is considered in the context of the common strategic goal of school education, which is to train in the general education system of highly moral, cultural, well-developed people. Thus, art lessons play an important role in the education and upbringing of the younger generation. There is, accordingly, a social demand for the training of teachers of fine arts, able to qualitatively solve the problem of aesthetic education in the general context of personal development. Thus, in China, as in Ukraine, the problem of training art teachers, who have a high level of not only teaching but also art, is acute.

In scientific sources, the interpretation of innovation as a science of creating pedagogical innovations, their evaluation and development by the pedagogical community, their use and application in practice is relatively stable $[9 ; 10]$. This rather young science studies the nature, patterns of development of innovations in the subjects of education, as well as provides a link between pedagogical traditions and the design of future education [4].

In the scientific and pedagogical discourse for the concept of "innovation" is characterized by multifaceted approaches to the interpretation of its essence, the leading among which are: the form of organization of educational activities; a set of new professional actions of the teacher, aimed at solving current problems of education and training from the standpoint of personality-oriented education; changes in educational practice; complex process of creation, distribution and use of a new practical tool in the field of engineering, technology, pedagogy, research; the result of the innovation process [3, p. 52]. 
Based on the analysis of psychological and pedagogical sources, we conclude that innovation in education is a process of creating, implementing and disseminating in educational practice new ideas, tools of pedagogical and management technologies, which increase the achievement of structural components of education. state [1].

Critical comprehension of scientific approaches to the interpretation of the essence and content of the concept of "innovation" testifies to a certain duality of views of Ukrainian and foreign scientists in this regard. Thus, according to one approach, innovation can be considered only something new that results in radical changes in a particular system. According to another approach, innovation can be understood as any, even insignificant, innovations as materialized ideas of possible increase of efficiency of educational system.

The procedural nature of the concept of "innovation" is reflected in a set of practical actions aimed at using scientific and technical results to obtain new or improve existing technologies, management methods [7, p. 9].

It is due to innovative activities, innovations, as noted by V. Kremin, a person is able to productive activities, to accept and adapt according to their urgent needs the results of this activity [8].

According to O. Voloshenko, innovative activity, being a complex and multifaceted phenomenon, its content covers the process of interaction of individuals, aimed at development, transformation of the object, its transfer to a qualitatively new state; systematic activities for the creation, development and application of new tools; a special kind of creative activity that combines various operations and actions aimed at obtaining new knowledge, technologies, systems [7, p. 40].

Psychological and pedagogical research has shown that innovative pedagogical activities involve the ability of educational entities to generate ideas, implement them, analyze monitoring data and produce new pedagogical ideas, publish results, provide conditions for their implementation in the education system [1, p. 33-34]. For full and effective development of innovative activity it is important to create conditions for creative development of a gifted person: material, informational, pedagogical, psychological.

L. Danylenko distinguishes between the concepts of "innovative activity" and "innovative educational activity". Under the innovative activity the author understands the process of introducing new elements into the traditional system, creating and using an intellectual product, bringing new original ideas to their implementation in the form of finished goods (services) on the market [3], and innovative educational activities - as a process of innovating learning. , education and management of institutions (institutions, 
organizations) of education. This understanding allows us to conclude that in order to carry out innovative educational activities, participants in the educational process need to put more effort and creativity; the success of individuals and organizations largely depends on their ability to produce and adopt innovations [6].

O. Kozlova considers pedagogical innovative activity as the highest level of pedagogical creativity, pedagogical invention, introduction of new in pedagogical practice [7].

Thus, it is legitimate to say that the integration of innovative and pedagogical activities will help the development of personality in the learning process, which becomes the core concept of the pedagogical process, the essential, in-depth concept of science and defines modern requirements for master training. Based on this, the main idea of innovation-oriented professionalization of future teachers of art disciplines to innovative activities is to impose students' theoretical knowledge of innovative processes on the "outline" of future professional activity by consistent modeling of subject and social content of pedagogical activities, projection of regulatory requirements for future professionals. in the plane of individual characteristics of students and construction on this basis of individual educational trajectories.

Thus, in the context of our study, we consider innovation as a complex, creative activity aimed at creating, implementing and disseminating innovations in pedagogical theory and practice [4]. In this context, the innovative educational activity of the future teacher of art disciplines to innovative activity is interpreted as the process of realization of innovative knowledge, skills, abilities, competencies at the level of study, testing, creation and application of educational innovations.

We fully agree with the position of I. Gavrish, according to which the preparation of students for innovative professional activities should be considered as a system, as it can be described as an ordered set of interconnected components, which is a holistic formation. Among such components of the system she names the purpose, content, methods, forms, means, etc. [1, p. 21]. In this context, the author considers the readiness for innovative professional activity as an integrative quality of personality, which is formed as a result of the psychological system of activity, and its structure the researcher considers identical to the structure of the corresponding functional psychological system. As components of such a system, I. Gavrish identifies the motives and goals of the activity, its information base and program, the decision-making unit and the subsystem of personality qualities, which is professionally important.

Pedagogical support of the process of preparation of the future teacher of art disciplines for innovative activity in China taking into account the above is carried out in the 
following directions: from dehumanization of spheres of public life to humanistic and personal orientation of education; - from knowledge to their personal significance; from passive assimilation of educational information to its active production; from the cognitiveinformative approach to the innovative-transformative one; from authoritarian pedagogy to pedagogy of equal partnership; from total unification and standardization of the educational process to its flexible modeling taking into account the individuality of the subject of study; from disintegration to integration into the world educational space [5, p. 3].

In pedagogical works the readiness of the future teacher for pedagogical activity is investigated as a multicomponent system (O. Moroz); integrated, stable education, which is a combination of all structural components of the individual psyche and is manifested in the focus on pedagogical activities (F. Gonobolin), acquisition and implementation of professional and pedagogical knowledge, skills, abilities (V. Slastyonin), development of pedagogical abilities , F. Gonobolin, V. Krutetsky, N. Kuzmina, Y. Kulyutkin, G. Sukhobska).

At the epicenter of research in acmeological science, readiness for innovation is considered as a basic category in achieving optimal results, which is expressed in terms of: level of activity, peaks, factors of productive activity (V. Antonov, A. Derkach, N. Kuzmina).

Summarizing the above and interpreting this definition from the standpoint of acmeological science, the innovative activity of the future teacher of art disciplines to innovative activity in China should be characterized as individual success in creating spiritual products, reaching peaks of personal abilities in performing, theoretical, artistic and pedagogical .

First of all, we should consider the stage of initial professional training, which is associated with the development of motivation, artistic, musical and creative abilities, musical thinking, emotional and volitional sphere (artistry); mastering the techniques and practical methods of activity in the field of art; mastering the basics of creative innovation. At this stage, personal and subjective qualities, creative potential, worldview are formed, which stimulate the development of the need to find innovative routes of professional development.

The second stage - "professional development" - is characterized by the formation of subject-object qualities of the future teacher of art disciplines to innovative activities, attitudes to self-development of creative potential, worldview, sense of professional responsibility in the development of art, involvement in high spirituality, priority of satisfaction of basic needs, self-improvement on the way to professionalism and skill from the point of view of the 
personality-oriented approach, mastering of necessary "palette" of ways of professional activity, display of productive competence.

At the stage of innovative and productive maturity there is a free independent design of the content of professional activity and processes of self-development, self-correction and self-improvement of the teacher; realization of personal and subjective positions, attitudes in the context of mastering artistic disciplines and pedagogical creativity; shifting the emphasis in activities from situational to supra-situational goals, covering the multidimensionality of artistic information; adoption of standards and criteria of self-esteem, professional ideals; awareness of the abilities that contribute to the achievement of professional acme, creative self-realization; mobilization of internal resources of creative potential and its transformation into innovative potential, which characterizes the highest level of professionalism as the peak of development of a specialist in the field of art. This stage is characterized by a stable manifestation of readiness for productive innovation as a sustainable quality of personality.

At the stage of professional skill, the activity corresponds to the established ideals, standards, criteria and norms in the field of art and education, as well as pedagogical innovation. The creative function of striving for high professional achievements as the peaks of innovative activity, which gain objective public recognition, is realized.

According to numerous studies by N. Kuzmina, effective ways to stimulate students to master the highest levels of innovative pedagogical activities include mastering the criteria as a means of assessing the effectiveness of solving pedagogical problems in monitoring the high-, medium-, low-productivity teachers of their profile [2]. Students' knowledge of the manifestations of pedagogical skills and creativity is actualized in terms of solving their own problem associated with the creation of a project of original, author's system of activities capable of ensuring the effectiveness of the educational process and creative self-realization. Creation of the project, its substantiation, partial check and protection - all these are ways of formation at future experts of pedagogical thinking as the most important element of development of readiness for innovative activity.

\section{Conclusions}

Thus, the acmeological orientation of the future teacher of art disciplines to innovation, his readiness and ability to innovate is ensured by the effectiveness of the latest advances in science, creative mastery of advanced pedagogical experience, finding the most rational means of optimizing the educational process and extracurricular activities. , problem research groups, societies, etc.). 
We see prospects for further research in the theoretical substantiation of forms, methods of means of preparation of the future teacher of art disciplines for innovative activity in China.

\section{References:}

1. Gavrish IV Theoretical and methodological foundations of formation of readiness of future teachers for innovative professional activity: author's ref. dis. ... Dr. Ped. Science: 13.00.04. Kharkiv, 2006. 46 p.

2. Grebenyuk G. Acmeology and culturology. Acmeology of development. Kyiv: Naukova Dumka, 2006. 161 p.

3. Danylenko LI Management of innovation in secondary schools: a monograph. Kyiv: Millennium, 2004. 358 p.

4. Dychkivska IM Innovative pedagogical technologies: textbook. 2nd ed., Ext. Kyiv: Akademvydav, 2012. 352 p.

5. Elbrecht OM Pedagogy of higher school: modular lecture-practical course. Kyiv: Europe Publishing House. un-tu, 2005. 78 p.

6. Encyclopedia of Education / ch. ed. VG Flint. Kyiv: Yurinkom Inter, 2008. 1040 p.

7. Kozlova OG Essential components of innovative activity of the teacher. Sumy: Dream, 1999. $90 \mathrm{p}$.

8. Kremin VG Education and science in Ukraine - innovative aspects. Strategy. Realization. Results. Kyiv: Gramota, 2005. 448 p.

9. 付八 军.校本 校本 培训研究 述评 / 付 八军 // 井冈山 学院 学报（哲学 社会 科学）. 2009. № 3. 页 114-117.

10. 代 荵华.专业专业 发展与 校本 培训/ 代荵华. 北京: 教育 科学 出版社, 2011. 214 页. 